

\title{
O RESPEITO AO DIREITO À VIDA VISTO PELOS ESTUDANTES UNIVERSITÁRIOS E SUA REPRESENTAÇÃO SOCIAL
}

RESPECT FOR THE RIGHT TO LIFE AS SEEN BY COLLEGE STUDENTS AND THEIR SOCIAL REPRESENTATION

Cinthya Amaral Santos

Doutoranda em Psicologia, pela Pontifícia Universidade Católica de Goiás. Mestra em Sociedade, Tecnologia e Meio Ambiente, pelo Centro Universitário de Anápolis. Especialista em Direito Constitucional e Eleitoral (UCG) e Docência Universitária (UCG); graduada em Direito (UniEVANGÉLICA - 1997).

Humberto César Machado

Pós-Doutor em Psicologia, pela Pontifícia Universidade Católica de Goiás (PUC GO, 20 I6). Doutor em Psicologia, pela Pontifícia Universidade Católica de Goiás (PUC GO, 20I3). Mestre em Psicologia, pela Pontifícia Universidade Católica de Goiás (PUC GO, 2006). Especialista em História, pela Universidade Federal de Goiás (UFG, 2002). Graduado em Filosofia, pela Universidade Federal de Goiás, 1996. Graduado em Pedagogia, pela ISCECAP, 2018.

Odesson Alves Ferreira Filho

Mestrando em Cognição humana e Pós-graduando em Psicologia positiva pela PUCRS. Graduado em Psicologia pela PUCGO. Psicólogo clínico atuando na área de avaliação psicológica e psicodiagnóstico. Pesquisador com publicações em linhas de pesquisa de Psicologia social.

\section{RESUMO}

A pesquisa "O direito à vida vista pelos estudantes universitários e sua representação social" está inserida no contexto do macroprojeto Constituição Federal, Direitos Fundamentais e Representação Social. Busca-se com essa proposta científica estudar o princípio do direito à vida na perspectiva representacional do acadêmico, abrangendo os cursos de Direito, Ciências Biológicas e Agronomia, do campus de Palmeiras de Goiás da Universidade Estadual de Goiás. Foi uma pesquisa promissora que trouxe conhecimentos teóricos a respeito do direito fundamental do conceito de vida para a nossa Constituição Federal, de 1988, e sua origem como direito fundamental de primeira geração, e é um dos direitos especificados e assim exposto no artigo $1^{\circ}$ da Carta Magna brasileira. A pesquisa também teve como objetivo analisar, utilizando-se a Teoria das Representações Sociais, qual o significado desse princípio para os estudantes, tanto na perspectiva social quanto na atuação do Estado, como defensor do interesse público. $\bigcirc$ estudo usou 
como metodologia de pesquisa de caráter qualitativo e quantitativo, bem como pesquisas bibliográficas e aplicação de instrumento de coleta de dados, com 126 sujeitos divididos da seguinte forma: 63 alunos do curso de direito; 26 alunos do curso de Ciências biológicas; e 37 alunos do curso de Agronomia. Foi utilizado o software Iramuteq para análise das frequências das palavras evocadas, bem como a análise de similitude e nuvem de palavras para aferição da questão subjetiva. Além das questões para verificação da representação social também foi realizado questionário sociodemográfico, com perguntas sobre idade, sexualidade e cursos de graduação. As contribuições científicas para este estudo foi a produção textual a respeito do pensamento representacional do acadêmico de três cursos de graduação diferentes. Ele buscou também analisar a respeito do sentido do fundamento vida, quanto à atuação do Estado no cumprimento de sua função social, e no aspecto de sua abrangência para o próprio ser humano.

PALAVRAS-CHAVE: Direito. Fundamento. Vida. Dignidade.

\section{ABSTRACT}

The research about the respect for the right to life as seen by university students and their social representation is inserted in the context of the macroproject, the Federal Constitution, Fundamental Rights and Social Representation. Through the scientific proposal, we have sought to study the principle of the right to life in the representational perspective of the academic person, comprising courses in Law, Biological Sciences and Agronomy, at the Palmeiras de Goiás Campus, University of Goiás. It was a promising study, which fetched theoretical knowledge about the fundamental rights and the concept of life based on our Federal Constitution of 1988, encompassing its source as fundamental right of a first generation, which is one of the specified rights and is exposed in article I of the Brazilian Magna Carta. Using the Theory of Social Representations, the project also aimed to analyze the meaning of this principle for students, both from a social perspective and in the performance of the State as a defender of the public interest. The study used as a research methodology, qualitatively and quantitatively, bibliographic references and a data collection application, carried out with 126 individuals divided as follows: 63 students from the Law Course, 26 from the Biological Sciences and, finally, 37 from Agronomy. Also, the Iramuteq Software was used to analyze the evoked words frequencies, as well as the Similitude and Word Cloud analysis to assess the subjective question. Besides the inquiries to verify social representation, a sociodemographic questionnaire was conducted, with questions about age, sexuality and undergraduate course.

KEYWORDS: Right. Plea. Life. Dignity. 


\section{INTRODUÇÃO}

O artigo e a pesquisa proposta têm como tema principal a análise da representação social dos acadêmicos em relação ao direito à vida. É um tema de abrangência mundial, baseado em estudos de doutrinas, jurisprudências e em pesquisa realizada com os estudantes sobre o que significa para eles ter direito à vida. É um direito fundamental resguardado pela Constituição Federal e de grande importância, principalmente quando se percebe a banalização desse fundamento pela própria sociedade.

É importante fazer uma abordagem bibliográfica a respeito dos conceitos de direitos fundamentais e do direito à vida, perfazendo também seu histórico e suas características. Além disso, é necessário fazer um estudo sobre a Teoria das Representações Sociais, dando-se destaque para as três condições atuais a serem percebidas, e que são: em primeiro lugar, a percepção que os alunos entrevistados têm em relação à situação e ainda sua classificação como reversível ou irreversível, a autonomia e o grau de interação que há entre a situação específica e a que é vivenciada; por fim, as cargas efetivas que são atividades na situação de referência para a memória da coletividade.

Para Abric (1998), o sujeito reconstitui a realidade com a qual ele se confronta, atribuindo significado específico por meio de um produto e o processo de sua atividade mental. Esse procedimento exige que se definam os objetos no contexto das relações sociais, no meio em que os homens vivem, interagem e atuam. $\bigcirc$ mesmo autor ainda defende que é um conjunto de opiniões, atitudes, crenças e informações referentes a um objeto ou a uma situação, sendo determinada pelo próprio sujeito e pelo contexto social em que ele atua.

Jodelet (200 I), em seus estudos, conceituou que as representações sociais são fenômenos definidos como uma construção da realidade comum, elaborado e compartilhado entre as pessoas, utilizando-se do conhecimento estruturado pela sociedade. Assim concluiu que existe uma necessidade de que a sociedade esteja informada sobre o que acontece no mundo, para dominá-los, identificá-los e resolver caso apresentem problemas.

\section{DOS DIREITOS FUNDAMENTAIS}

É de sua importância estudar o contexto histórico dos direitos fundamentais, assim se torna mais compreensível o mundo jurídico, bem como o que é essencial à pessoa humana. Serão abordadas nesse tópico também as dimensões, que hoje já podem ser agrupadas em quatro, tendo cada uma sua devida particularidade. 


\section{I Evolução histórica dos direitos fundamentais}

Não pode haver compreensão precisa a respeito dos direitos humanos se não se verificar em qual tempo e sociedade eles surgiram. São normas construídas ao longo do tempo, que têm como bases teóricas as lutas pelo poder ( $\mathrm{BOBBIO}$, 1992). José Joaquim Gomes Canotilho (2004) entende que os destinos dos direitos fundamentais estão presentes na histórica política, em que predominam as novas ideias, ideologias dominantes de uma consciência social e coletiva, bem como a cultura política de determinado período da história. Sendo assim, eles nascem das lutas dos seres humanos contra o poder arbitrário e a opressão. Essas condições passam a ser necessárias e imprescindíveis para proteger o cidadão e dar a ele uma existência digna.

$\mathrm{Na}$ evolução das sociedades, têm-se na idade antiga, destacando-se o Egito Antigo e a Mesopotâmia, alguns mecanismos que protegiam a população de forma individual. O documento mais importante, datado de 1690 a.C. foi o Código de Hamurabi, considerado por muitos doutrinadores como a primeira codificação a estabelecer direitos comuns ao homem, dentre eles propriedade, honra, família, e também a supremacia da lei sobre qualquer desmando dos governantes (CASTILHO, 20I0).

Importante também salientar as cidades da Grécia, nas quais se aplicava que as normas jamais poderiam ser desconsideradas, mesmo pelos governantes. Essas medidas se fundavam na existência humana que poderia reivindicá-las. Contudo, o Direito Romano foi o pioneiro em apresentar uma série de interditos que tinham como objetivo barrar os arbítrios estatais. Os estatutos criados davam ênfase às liberdades clássicas, e receberam o nome de primeira geração de direitos. $O$ mais importante deles foi a Lei das Doze Tábuas, que normatizou a propriedade, a liberdade e a proteção ao cidadão (CASTILHO, 20 I0).

A Idade Média revelou pensadores de formação cristã, que, voltados para os dogmas religiosos, exercitavam sua fé e balizavam os fundamentos humanos. Esse período caracterizou-se por dar ao ser humano valores próprios, que estão expressos na ideia da dignidade como bem inalienável e incondicionado. A idade moderna deu ênfase ao núcleo central dos direitos, e colocou a vida, a propriedade e a liberdade como normas fundamentais. Os documentos de destaque desse período foram o Petition of Rights, que normatizava a possibilidade de uma petição para que nenhum homem livre fosse detido ou aprisionado; e o Habeas Corpus Act, que previa uma reclamação escrita ou requerimento para alguém que fora acusado de um crime ou estivesse detido (PIOVESAN, 20 I2).

A idade Contemporânea é inaugurada com a Revolução Francesa, de 1789. A autora acima citada fez uma análise dos principais destaques escritos na Declaração dos Direitos do Homem e do Cidadão, que previu que as Constituições Nacionais instituíssem os direitos humanos e a obrigação de todos os Estados respeitarem 
a Declaração Universal. A partir desses princípios, buscou-se garantir uma convivência pacífica e conceder o direito de segurança, liberdade e propriedade aos indivíduos.

No Brasil, após o período do militarismo que durou vinte e um anos, e a partir do processo de redemocratização, houve a necessidade de elaboração de uma nova ordem Constitucional com o objetivo de refazer o pacto político-social. Em cinco de outubro de 1988, foi promulgada a Constituição da República Federativa do Brasil. A nova Constituição trouxe um avanço em relação às garantias e direitos fundamentais, e buscou dar destaque à proteção social e ao mínimo existencial (MORAES, 2007).

\subsection{Direito fundamental e suas gerações ou dimensões}

Há várias terminologias para se referir aos direitos fundamentais, como "direitos humanos" e "direitos dos cidadãos", mas a mais sedimentar ou adequada é a utilizada no título normatizado na Constituição Federal, acima especificado. São normas básicas de todo cidadão e representam as liberdades públicas, valores eternos e universais. Não deixam de ser imposições estatais que visam proteger a população.

Importante ponto a ser discutido é o que são os direitos fundamentais e por que são divididos em gerações ou dimensões. São preceitos que têm como objetivo assegurar aos seres humanos uma existência digna, igualitária e com liberdade, no sentido de criar sempre condições melhores à existência humana. $\bigcirc$ jurista Alexandre de Moraes (20I5) conceitua direitos fundamentais como sendo a institucionalização de normas e garantias para os seres humanos que devem protegê-los do arbítrio do poder estatal e estabelecer condições mínimas de vida e desenvolvimento social.

Kasel Vasak foi o primeiro constitucionalista a propor a triangulação dos direitos humanos em gerações ou dimensões. Em sua palestra proferida na conferência Internacional de Direitos Humanos, ocorrida em Estrasburgo, em 1979, que teve como inspiração o lema "Revolução Francesa", o autor fez um estudo das normas fundamentais por meio de um processo histórico de institucionalização, esquematizando-os em primeira, segunda e terceira gerações (BONAVIDES, 20 I7).

Os de primeira geração, classificação que abrange o direito à vida, têm como início histórico os movimentos liberalistas ocorridos no século XVIII. Equivalem às liberdades individuais em sentido amplo e às prestações negativas por parte do Estado. Este deve proteger a autonomia do ser. Recebem também a nomenclatura de "direitos de defesas", pois têm a função precípua de defender o indivíduo contra qualquer tipo de intervenção ilegal por parte do Poder Estatal (RAMOS, 20 | 4).

Paulo Bonavides (2018) refere-se aos direitos fundamentais de primeira dimensão como aqueles que representam as normas civis e políticas. Representam 
a fase inicial do processo de constitucionalismo ocorrido no ocidente e continuam a fazer parte das Constituições democráticas atuais. Destacam-se como direitos de proibição ao Estado, para que não se permita o abuso de Poder. À administração são impostas obrigações de não fazer o que limita o poder público em relação à pessoa.

A segunda geração de direito teve início com a queda do Estado Liberal, o que culminou com o nascimento do Bem-Estar Social. Advieram da ideologia antiliberal e se firmaram no princípio da igualdade, do qual são agregados e não podem se separar, sob pena de serem destruídos em sua própria razão de ser. O marco principal foi a Revolução Industrial, ocorrida no século XIX, na Inglaterra, em que o proletariado iniciou processos de luta em busca da defesa dos direitos sociais (BARROS, 2017).

Quando se fala em terceira geração ou dimensão, está-se referindo aos princípios da fraternidade e da solidariedade. Esses direitos protegem interesses coletivos ou difusos, não visando ao sujeito isolado, mas sim a um grupo, e possuem uma preocupação com a presente geração e as futuras. Paulo Bonavides (20।6) ensina que eles têm características de humanismo e universalidade, tendo como destinatário a coletividade como valor supremo.

Mais recentemente surgiu a ideia dos direitos de quarta geração que são os ligados ao pluralismo, democracia, informação e ao respeito das minorias. Eles estão conectados com os de segunda e terceira gerações, e absorvem a subjetividade dos de primeira geração. Para que todas as gerações tenham plena efetividade, eles têm de se inter-relacionarem e se otimizarem (NOVELINO, 20।8).

\section{DO DIREITO À VIDA}

É importante, do ponto de vista doutrinário, estudar sobre os aspectos da historicidade do direito, o direito fundamental de viver, bem como mostrar os conceitos de vários doutrinadores e estudiosos que buscam, por meio de estudos aprofundados, o conhecimento técnico do fundamento a ser estudado.

\section{I Historicidade}

O direito à vida foi positivado em Constituições ao redor do mundo, mas essa norma sofreu alterações no decorrer da histórica humana, e em muitas situações deixou de ter valor, quando do contexto de guerras e genocídios. $\bigcirc$ primeiro documento que trata desse fundamento é a Lei de Talião, na Babilônia, em I780 a.C., cujo princípio delimitador era "olho por olho e dente por dente". Isso significava dizer que quando um ser humano cometia algum crime podia sofrer torturas ou pagar com a própria vida. 
Azambuja (20 I I) destaca os permeios da vida na Grécia Antiga e explica que, apesar de viver uma democracia, a maioria da população era formada de escravos, estes não tinham nenhum direito. Em Roma só existia o respeito à vida humana para os cidadãos, mas mulheres, estrangeiros e crianças não eram considerados, portanto, abrangia apenas os homens.

No cenário cristão, inicia-se uma ideia de igualdade entre os homens com reconhecimento da vida. Tomás de Aquino professou a existência de ordens diferentes, a principal destacava a racionalidade do ser humano, que dava o direito à população de que, em caso desobediência ao direito natural por parte dos governantes, a população poderia resistir. Nesse período também a maiores atrocidades foram verificadas em nome de Deus, e só o documento, de 1215, do Rei João Sem Terra, intitulado Magna Carta Libertatum, é que os primeiros direitos fundamentais surgiram (SARLET, 2009).

Na era moderna, o pós-guerra mostrou a necessidade de uma ação internacional em conjunto para normatizar direitos fundamentais aos seres humanos. Em 1948, pós-Segunda Guerra Mundial, cria-se o preâmbulo da Declaração Universal dos Direito Humanos, em que se delineou uma perspectiva universal de proteção e de garantias universais. Destacam-se alguns artigos que retratam o direito à vida. Por exemplo, o artigo 10 do documento delimita que todos os Estados que sejam signatários possam reconhecer, pelas medidas de proteção para as crianças e aos adolescentes, tanto os aspectos econômicos quanto sociais.

Reforça também que crianças e adolescentes não podem ser submetidos a trabalhos que prejudiquem a saúde moral e física. Outro destaque está normatizado no artigo II, que reconhece que toda pessoa tem direito a vida digna, com o mínimo adequado a manutenção de sua família, em relação à alimentação, vestimenta e moradia (ONU, 1966).

Na Convenção Americana de Direitos Humanos, nominada Pacto de San José da Costa Rica, o direito à vida tem sua normatização no artigo $4^{\circ}$, que especifica que toda pessoa tem direito a ter sua vida respeitada, e essa norma fundamental deve ser protegida por lei, abrangendo desde o momento da concepção até a morte do indivíduo. Complementa ainda que ninguém possa ser privado dela de modo arbitrário (OEA, 1969).

\subsection{Conceito}

direito à vida encontra-se no rol dos direitos e deveres individuais e coletivos da Constituição Federal, de 1988, no Capítulo I, e é considerado como direito de primeira geração, tamanha sua relevância para a humanidade. Para Paulo Gonet Branco (20 |3), proclamar o direito à vida deve fazer parte do ordenamento jurídico e se justifica por ser um valor supremo do ser humano. A ordem Constitucional 
de um Estado, que orienta e informa os cidadãos, deve incluir esse direito no rol dos demais, dando-lhe a dimensão primária na Carta Magna brasileira.

É o pressuposto básico de todos os demais direitos e liberdade. Foi normatizado na Constituição Federal da República Federativa do Brasil, em 5 de outubro de 1988, no caput do artigo $5^{\circ}$, e veio acompanhado de outros direitos, como liberdade, igualdade, segurança e propriedade (BRASIL, 1988).

Estado tem o dever de resguardar a vida, desde a concepção até a morte, sendo esse direito o alicerce jurídico do cidadão. É fundamental, primordial e a base para todos os outros direitos. Moraes (2017) ainda afirma que é a partir da vida que se forma a base para a dignidade humana, a liberdade e a integridade física. E reafirma que é a mais importante de todas as normas, regente da proteção específica a uma vida digna, desde o nascimento, durante a existência e até ao seu fim.

Nessa mesma linha de raciocínio, destaca-se:

A existência humana é o pressuposto elementar de todos os demais direitos e liberdades disposto na Constituição e que esses direitos têm nos marcos da vida de cada indivíduo os limites máximos de sua extensão concreta. $\bigcirc$ direito à vida é a premissa dos direitos proclamados pelo constituinte; não faria sentido declarar qualquer outro se, antes, não fosse assegurado o próprio direito estar vivo para usufruí-lo. $O$ seu peso abstrato, inerente à sua capital relevância, é superior a todo outro interesse (BRANCO, 2010, p. 44I).

Na sequência conceitual destacam-se duas facetas, quais sejam: o direito de defesa e o dever de proteção. $\bigcirc$ primeiro significa uma imposição ao Poder Público e também às pessoas, no sentido de impedir que esse bem seja agredido. $\bigcirc$ segundo já sustenta uma imposição somente ao Estado, e que devem ser tomadas todas as providências para garantir a proteção da vida das pessoas. $\bigcirc$ ordenamento jurídico brasileiro revela várias proteções, principalmente na seara penal. $\bigcirc$ Estado tem o dever de agir de forma constante para promover a realização da proteção ao direito à vida (BULOS, 2012).

$\mathrm{Na}$ análise de importância, chega-se à conclusão de que se esse direito não for respeitado, todos os outros perdem o sentido de existir. André Ramos Tavares (20 I 8) também percebe as duas vertentes e especifica que a primeira significa o direito de não morrer, e a segunda que é o ser humano possuir um adequado nível de existência, ou seja, o chamado mínimo existencial. A vida só pode ser interrompida por causas naturais, é proibido tirar a vida de outrem, reflexo da primeira faceta. Já a segunda reflete-se na necessidade de garantir saúde, alimentação, educação para todos sem distinção.

A jurisprudência do Supremo Tribunal Federal confere ao direito à vida um sentido amplo, ao ser humano precisa ser resguardada uma existência digna. Ele 
se relaciona com outros direitos e é o núcleo material da dignidade humana, fundamentos da República Federativa do Brasil, artigo $1^{\circ}$ da Constituição brasileira, de 1988. A partir desses pressupostos, o Estado deve deter todos os meios práticos para assegurar uma vida sublime (BARROSO, 20I I).

Apesar de ser o principal direito fundamental existente e o primeiro a ser protegido, pode sofrer restrições pela própria legislação. Existem várias normas nas leis brasileiras ou entendimentos que especificam as limitações impostas ao direito de viver. Um exemplo é a defesa da própria existência, a pessoa humana não pode ser punida por tentar ou tirar a sua vida. $\bigcirc$ Poder Público, nesse aspecto não pode interceder. Outros casos que também merecem destaque são os relacionados à legitima defesa e ao estado de necessidade, excludente de ilicitude, que impedem o Poder Judiciário de punir quando há a comprovação de que uma pessoa tirou a vida de outra, mas para defender a si própria (TAVARES, 20। 8).

\section{METODOLOGIA}

A presente pesquisa é qualiquantitativa e é orientada pela Teoria das Representações Sociais. Essa teoria possibilita ao pesquisador visualizar a interpretação dos participantes da realidade que se pretende estudar, o Direito à Vida, o que gerou a possibilidade de se compreender atitudes e comportamentos de um grupo social escolhido entre alunos de três cursos superiores da Universidade Estadual de Goiás.

A amostra da presente pesquisa foi constituída por 126 alunos, de três cursos superiores, Ciências Biológicas; Agronomia e Direito, da Universidade Estadual de Goiás, Unidade Palmeiras de Goiás. Foram entrevistados 65 alunos do curso de Direito; 25 alunos do curso de Biologia, e 36 alunos do curso de Agronomia.

$\mathrm{Na}$ coleta de dados, foi feito um questionário composto de uma questão de evocação, usando como termo indutor "Direito à Vida". $\bigcirc$ aluno teria de especificar as cinco primeiras palavras que the vinham à mente, a respeito da expressão indutora e também justificar as duas primeiras palavras evocadas. Foram feitas também, em um segundo momento, duas questões utilizando-se a escala Likert e, por fim, uma questão subjetiva, em que se pediu ao aluno, que explicasse o que significava para ele a expressão "Direito à Vida".

Por fim, na segunda parte do questionário foram apresentadas questões sobre dados Sociodemográficos dos entrevistados, dados estes coletados em 2019. Para o tratamento dos dados foi utilizado o Software IRaMuTeQ, desenvolvido por Pierre Ratinaud, o qual auxilia nas análises estatísticas sobre corpus textuais, e também sobre tabelas, indivíduos e palavras. 


\section{I Dados Sociodemográficos}

A amostra da presente pesquisa foi constituída por 126 alunos, de três cursos superiores, Ciências Biológicas; Agronomia e Direito, da Universidade Estadual de Goiás, Unidade Palmeiras de Goiás. Foram entrevistados 63 alunos do curso de Direito, dos $2^{\circ}$ e $4^{\circ}$ períodos; 26 alunos do curso de Ciências Biologicas, $6^{\circ}$ e $8^{\circ}$ e 37 alunos do curso de Agronomia, distribuídos entre os $2^{\circ}$ e $5^{\circ}$. Os dados Sociodemográficos da pesquisa foram especificados na seguinte ordem:

Em relação à idade, foram entrevistados alunos entre as idades de 18 até 60 anos de idade. Em percentual, a grande maioria dos estudantes, total de 56,34\%, equivale a faixa etária entre 21 e 30 anos de idade. Com 23,80\%, 30 acadêmicos que responderam ao formulário estavam na faixa entre 15 e 20 anos. Com idades entre 3 I e 40 anos, houve I 4 participantes, o que equivale a um total de I I, I I\%. O restante, apenas I I alunos, entraram na faixa entre 4 I e 60 anos, o que revelou um percentual de $8,73 \%$. No âmbito geral dos entrevistados, 75 mulheres responderam ao questionário, o que equivale a 59,52\%; e 52 homens, equivalente a $41,26 \%$ do total.

\subsection{Discussão e resultados}

Pelo Software Iramuteq foi realizado um estudo matricial em relação à questão de evocação, em que se pediu aos sujeitos que revelassem as cinco primeiras palavras que lhes vinham à mente quando escutavam a expressão "Direito à Vida". Seguem abaixo os resultados alcançados e a análise pormenorizada com a devida explicação.

\subsection{Análise de frequência de palavras}

Utilizando-se a análise de frequência do programa Iramuteq foram detectadas quatro palavras repetidas várias vezes, e que se destacam nas primeiras posições, sendo elas:

Tabela I: Palavras mais evocadas e percentual de evocação

\begin{tabular}{|l|l|l|}
\hline Palavra Evocada & Percentual & Média de Evocação \\
\hline Liberdade & $7,2 \% \%$ & 9 vezes \\
\hline Educação & $10,04 \%$ & 5 vezes \\
\hline Segurança & $5,69 \%$ & 7 vezes \\
\hline
\end{tabular}




\begin{tabular}{|l|l|l|}
\hline Qualidade & $0,81 \%$ & I vez \\
\hline
\end{tabular}

Fonte da autora

Pela análise dos relatórios informados pelo programa Iramuteq, a palavra de destaque que se relaciona e se interliga com outras é o vocábulo "Liberdade". Na sequência: Educação, Segurança e Qualidade. A liberdade é o direito de fazer o que quer, estar livre para ir ou ficar, ter o domínio sobre seu corpo, seus pensamentos e também sua vida. Essa ideologia também é perceptível quando se vê a evocação das palavras aborto e livre-arbítrio, que retratam bem essa liberdade como ponto principal para os acadêmicos. Eles buscam ter vida e poder usá-la como bem lhes aprouver.

Outra palavra que se destacou, apesar de poucas evocações, mas sempre especificada nas primeiras posições foi "Educação". É necessário ter conhecimento sobre o direito e a garantia de que o Estado deve promover, a respeito de concessão, uma existência digna e proteção para que o cidadão possa viver. Ao mesmo tempo reflete o entendimento a respeito das normas que resguardam esse fundamento.

Outro ponto destacado pelos acadêmicos foi "Segurança". Na representação dos alunos, para se ter vida é necessária a segurança pública praticada pelo Estado, que é uma ação exercida para a proteção da dignidade e dos direitos fundamentais da pessoa. Esse entendimento dos acadêmicos leva à interpretação de uma possível representação do direito à vida unida aos preceitos da segurança pública. Cabe ao Estado dar garantias pessoais e de existência para a sociedade, isso inclui resguardar a vida digna e o direito de não ser o cidadão morto.

Os acadêmicos também destacaram a importância da "Qualidade" para se resguardar o direito à vida. A busca por ela deve partir do poder público e ser uma preocupação constante, priorizando mais o aspecto qualitativo em vez do quantitativo. Desenvolver um bom atributo em relação à saúde, meio ambiente e trabalho traz novos paradigmas para controle de doenças, dando valia a ações de prevenção, tratamento, reabilitação e promoção. Tudo isso reflete na vida saudável e com qualidade.

\subsubsection{Análise das questões utilizando o método Likert}

No questionário apresentado aos acadêmicos, foram feitas duas perguntas utilizando-se o método Likert. A primeira delas refere-se à existência de leis no Brasil e na íntegra questionou se "O Estado brasileiro, em relação ao direito à vida, como direito fundamental, possui leis que sejam eficazes". A escala utilizada foi do número um "Muito eficiente" até o número sete "Pouco eficiente". 
Gráfico I: Leis no Brasil

\section{LEIS NO BRASIL - VIDA}



Fonte: Dados da autora

Pela análise gráfica, Gráfico I, percebe-se que os acadêmicos não acreditam na eficiência das leis brasileiras de proteção ao direito à vida. Apenas 3 estudantes marcaram essa assertiva, o que equivale a 2,5\% do total entrevistado. No oposto, número sete da escala, que demonstra uma total ineficiência, o percentual também foi baixo, 4 acadêmicos marcaram essa assertiva, 3,04\% do total. Isso mostrou que poucos desacreditam totalmente que as normas brasileiras são eficazes para manutenção, proteção e resguardo da vida humana. A maioria dos sujeitos optaram pelo meio termo, 32,5\%, 39 alunos, marcaram a opção 4, exatamente a média entre a eficácia total e a ineficiência total. Conclui-se que para eles as leis não protegem a vida em sua totalidade. Existem leis, mas elas não refletem as reais necessidades para a situação de qualidade, segurança, saúde, liberdade para a população brasileira.

A segunda questão apresentada foi: "A sociedade se beneficia de condições mínimas dignas que o Estado Ihes proporciona, para garantia do direito à vida digna". O método Likert utilizou uma escala de sete números, sendo o número I a resposta "Sim Muito" até o número 7 "Sim Pouco". Pela análise do Gráfico 2 , percebe-se que os sujeitos da pesquisa não acreditam que a sociedade tenha condições mínimas de vida.

Não há por parte do Estado ações em relação à segurança, saúde e outros aspectos que tragam dignidade à existência humana. No polo oposto, temos 5,6\%, 7 acadêmicos acreditam que não há eficiência alguma na atuação do Estado, no 
cumprimento de proporcionar garantia desse direito à sociedade. A maioria dos alunos, 34 respostas, 27,20\%, assinalaram a assertiva 5, que se encontra no meio da escala. Isso pode demonstrar que há uma crença de que a Administração Pública fornece condições mínimas, mas não com eficiência máxima.

\section{Gráfico I: Leis no Brasil}

\section{VIDA DIGNA}



Fonte: Dados da autora

\subsubsection{Análise textual}

No questionário utilizado na presente pesquisa, foi formulada uma pergunta subjetiva, qual seja: "Para você, o que significa ter direito à vida". Para a discussão dos resultados foram utilizadas duas técnicas do Software Iramuteq, a nuvem de palavras que faz uma organização destas em forma de gráficos, sendo uma análise lexical mais simples, e a similitude, que é utilizada de forma mais frequente no contexto dos estudos em representação social. Esta possibilita identificar a coocorrência entre as palavras em destaque e suas interações com outros vocábulos.

A nuvem de palavras, Figura I revelou que, nas respostas dos sujeitos pesquisados, a possível representação social dos acadêmicos baseia-se nas seguintes palavras: "direito"; "vida"; "viver"; "digno"; "saúde". As palavras transcritas foram colocadas em ordem de importância. Percebe-se que na Figura I a palavra Direito está no centro, seguida de vida, escrita logo acima. A interpretação que se destaca é a de que os sujeitos da pesquisa deixam claro que a vida é um direito fundamental, uma norma de primeiro grau inerente ao ser humano. 


\section{回员】STA ESMAT}

Os outros vocábulos, que também aparecem circulando "Direito e Vida", mostram que os acadêmicos acreditam que para que esse fundamento Constitucional seja respeitado é preciso que o cidadão viva com saúde e tenha uma existência digna. Para que isso se torne realidade, o Estado tem o dever de conceder liberdade, qualidade, moradia, alimentação e educação. Essas condições básicas aparecem ao redor do núcleo central da nuvem de palavras, mas é a partir delas que se conseguirá ter esse direito respeitado pela administração pública e também pela própria sociedade.

FIGURA I: Nuvem de palavras

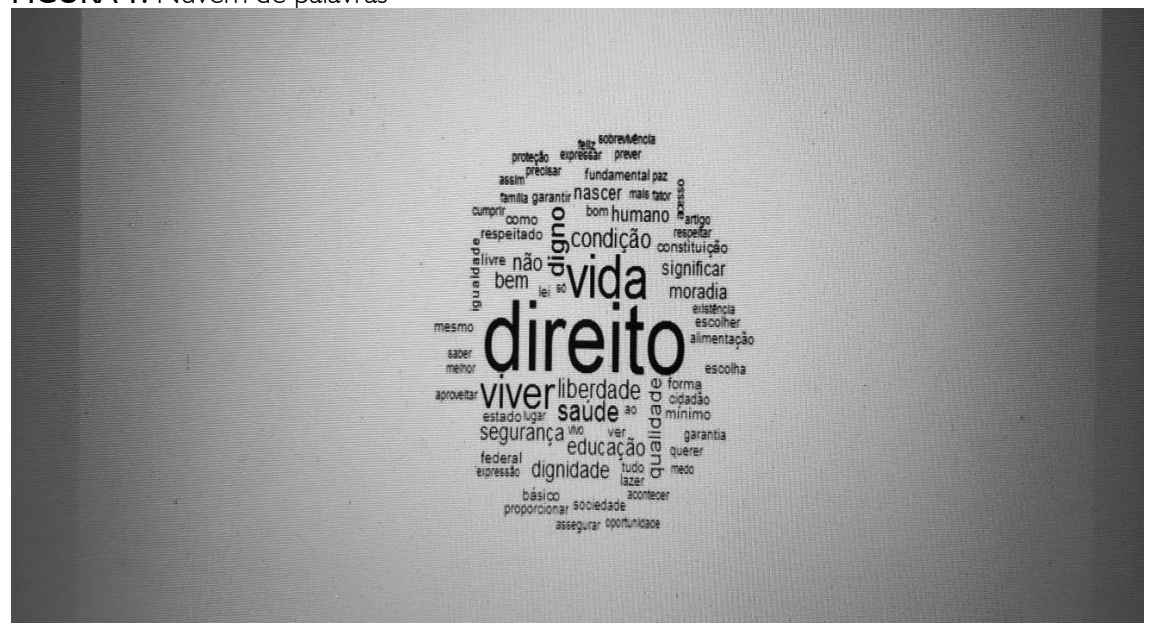

Fonte da autora

A segunda análise textual utilizou o programa Similitude. Este gerou uma árvore máxima, Figura 2 que trouxe os seguintes aspectos de análise:

Figura 2: Árvore Máxima - Direito à Vida 




Fonte da autora

A Árvore Máxima mostrou duas ramificações importantes, dando-se destaques a duas palavras, Direito e Vida. A primeira divisão, no lado esquerdo da figura, mostra a palavra direito como destaque central. A partir deste vocábulo ramificaram-se várias outras expressões que dão interpretação ao seu significado. $\bigcirc$ direito é um dever do Estado e deve ser respeitado e garantido para a sociedade. É fundamental que haja liberdade e que a sociedade possa viver bem.

No tronco principal da árvore, lado direito da Figura 2 aparece a palavra "vida". A conexão com o direito demonstra que eles estão interligados no mesmo ramo principal, a existência é uma norma fundamental. Para se alcançar uma vida digna, as ramificações do segundo tronco mostram que é necessário ter dignidade, mínimo existencial, boas condições, educação, saúde e qualidade.

A dignidade tem de ser proporcionada com o mínimo de condições possíveis a serem asseguradas pelo Estado. A saúde interliga-se com o cidadão possuir pelo menos moradia e boa alimentação. A qualidade é adquirida se houver acesso básico que reflita na oportunidade e melhor aproveitamento das funções estatais.

\section{CONCLUSÃO}

objeto pesquisado é um fundamento dos direitos humanos que possui como característica a historicidade, pois sofre uma longa jornada pela história mundial. Foi normatizado pelas Constituições, desde que as primeiras escritas surgiram, com as Revoluções Norte Americana e Francesa. No século XX, a mola 
propulsora foi as duas grandes Guerras, que levaram ao extermínio de milhares de pessoas na Europa.

Construir a representação social em relação ao pilar dos Direitos Humanos à vida, não pode ocorrer de forma isolada. Foi necessário um pensar crítico para se perceber o pensamento dos sujeitos da pesquisa em relação a esse posicionamento. Por ser socialmente construída, essa ideologia comum atendeu aos interesses preestabelecidos em sociedade; no caso em tela, dos acadêmicos entrevistados.

A pesquisa sobre a representação social dos acadêmicos em relação ao Direito à vida revelou que essa norma é uma garantia constitucional fundamental e se estende a todos as pessoas, nacionais ou estrangeiras residentes no território brasileiro, e está relacionada ao tronco principal donde decorrem todas as outras.

Cabe ao Estado garanti-la, por meio de ações de saúde, segurança pública, valores sociais, dando condições adequadas ao ser humano de viver com dignidade. Significou também para os acadêmicos que vida significa ter liberdade, educação, segurança jurídica e pública e, por fim, qualidade.

É preciso elaborar a construção de um modelo estatal que realmente assegure uma vida digna e um mínimo existencial num País de tantas desigualdades sociais. Ser um direito fundamental, base ideológica e legal para todos os outros, foi defendido pelos alunos por suas respostas em relação ao que significaria ter vida. Ao mesmo tempo materializar essa realidade só será possível quando o Estado conseguir proporcionar normas mais eficientes que permitam fornecer qualidade, dignidade e uma organização social mais justa e igualitária.

\section{REFERÊNCIAS}

AZAMBUJA, Darcy. Teoria Geral do Estado. $36^{\circ}$ ed. Globo. Rio de Janeiro, 201 I .

BARROS, Sérgio Resende de. Três Gerações de Direitos. Disponível: Acesso em: 16 de junho de 2017.

BARROSO, Luís Roberto. Curso de Direito constitucional contemporâneo: os conceitos fundamentais e a construção do novo modelo. 3. ed. São Paulo: Saraiva, 2011. p. 199.

BRANCO, Paulo Gonet; MENDES, Gilmar Ferreira. Curso de direito constitucional. 8. ed. São Paulo: Saraiva, 2013.

BULOS, Uadi Lammêgo. Curso de Direito constitucional. 7. ed. rev. e atual. de acordo com a Emenda Constitucional n.70/20 I2. São Paulo: Saraiva, 2012. 
BOBBIO, Norberto. A Era dos Direitos. I. Ed. 12. Tir. Rio de Janeiro: Campus, 1992.

BONAVIDES, Paulo. Curso de Direito Constitucional. $19^{a}$ Edição, São Paulo: Editora Malheiros, 2016.

CASTILHO, Ricardo. Direitos humanos: processo histórico - evolução no mundo, direitos fundamentais: constitucionalismo contemporâneo. I. ed. São Paulo: Saraiva, 2010.

MORAES, Alexandre de. Direitos humanos fundamentais: Teoria Geral. $4^{\mathrm{a}}$ ed. São Paulo: Atlas, 2007.

NOVELINO, Marcelo. Direito Constitucional. São Paulo: Editora Método, 2009, 3 ed.

PIOVESAN, Flávia. Direitos Humanos e o Direito Constitucional Internacional. 13. ed. São Paulo: Saraiva, 2012.

OEA - ORGANIZAÇÃO DOS ESTADOS AMERICANOS. Pacto de San José da Costa Rica. Disponível em: https://www.cidh.oas.org/basicos/portugues/c.convencao_americana.htm. Acesso em: 19 de outubro de 2020.

RAMOS, André de Carvalho. Curso de Direitos Humanos. São Paulo: Saraiva, 2019 , p. 57.

SARLET, Ingo Wolfgang. A eficácia dos direitos fundamentais. Porto Alegre: Livraria do Advogado, 1998.

TAVARES, André Ramos. Curso de direito constitucional. 7. Ed. São Paulo: Saraiva, 2018 . 


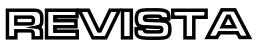

ESMAT 